\title{
Light weighting opportunities and material choice for commercial vehicle frame structures from a design point of view
}

\author{
Peter Seyfried · Ed Juarez Mendes Taiss • \\ Alexandre Costa Calijorne $\cdot$ Fei-Peng Li $\cdot$ \\ Qi-Feng Song
}

Received: 12 January 2015/Accepted: 23 January 2015/Published online: 5 March 2015

(C) The Author(s) 2015. This article is published with open access at Springerlink.com

\begin{abstract}
This paper focuses on an estimation of light weighting opportunities for the frame structure of commercial road vehicles. This estimation is based on simplified static load cases which play a predominant role for the dimensioning of a frame structure and therefore these simplifications are not putting the general validity of the conclusions into question. A comparison of different materials under this scenario shows that light metals do not show any weight reduction advantage in comparison to steel while a material-independent topology optimization has more weight reduction potential for the frame structure than a simple change of materials. Considering the constraints of part complexity which is directly linked with production and assembly cost, the ladder frame structure has become the current state of the art design. Thus the paper also puts a spotlight on basic rules of node design and vertical load induction in order to keep the weight of such a design as low as possible. Practical examples from manufacturers show that the weight of a commercial
\end{abstract}

P. Seyfried $(\bowtie)$

Hamburg University of Applied Sciences, Hamburg, Germany

e-mail: peter.seyfried@haw-hamburg.de

E. J. M. Taiss

Companhia Brasileira de Metalurgia e Mineração, Villa Nova, MG, Brazil

\section{A. C. Calijorne}

Caltra Projetos \& Consultoria, Belo Horizonte, MG, Brazil

F.-P. Li

Dongfeng Commercial Vehicle Technology Center, Shiyan, People's Republic of China

Q.-F. Song

FAW Technology Center, Changchun, People's Republic of China vehicle could be reduced by $10 \%$ and main parts of the frame structure could be reduced by $30 \%$ using high strength steel in combination with innovative production methods like roll forming.

Keywords Ladder frame $\cdot$ Light weighting $\cdot$ Commercial vehicle $\cdot$ Node design $\cdot$ High strength steel $\cdot$ Profile section $\cdot$ Vertical bending $\cdot$ Topology optimization

\section{Design requirements for frame structures}

The frame structure of a commercial vehicle to which all parts and modules are attached is the central interface of the entire vehicle. It is usually produced in high volumes for commercial road vehicles, which are completed by the original equipment manufacturer (OEM) with a cabin, axle and power-train modules to a drivable chassis. This drivable chassis is then completed with different superstructure variants by small and mid-size companies in low volume production depending on the special use of the vehicle. Thus the frame has to be easily adaptable for different kinds of superstructures and has to bear different load spectra imposed by these different types of superstructures.

The main load case for commercial vehicles is vertical bending. For the calculation of this load case the truck can be reduced to a 2-dimensional (2D) static model of a beam resting on two supports, which is vertically bent by a single or evenly distributed vertical load originating from the superstructure and the cargo. Dynamic forces caused by road bumps as well as abuse such as vehicle overloading are incorporated into the static model by multiplication of the static load with an impact factor which is based on experience. This factor is usually assumed to be 1.3 for conventional road vehicles in Western Europe, but it can be 
as high as 2 to 3 in emerging markets. It also depends on local market requirements and customer behavior.

The frame structure has to be flexible to accommodate torsion movements with deformation angle up to $20^{\circ}$ especially for the use in construction or mining areas. In other cases it is combined with stiff superstructures such as boxes. In these cases the deformation angle of the frame usually does not exceed $2^{\circ}$, which is standard for paved road while the main share of the torsion is taken up by the axle suspension [1]. The assembly of hang-on parts as well as cables has to be easy-going. Also coating and corrosion protection of the structure should be feasible in a simple process with low cost.

Experience reveals that the optimal, i.e., the most flexible and cost efficient design for a commercial vehicle structure concerning the aforementioned requirements is the so-called ladder frame structure. It consists of two longitudinal beams with an open U-shaped section, which are laterally connected by preferably equidistant cross members with either closed or open sections. These give the whole construction in the planar view the typical ladder shape. In some special cases the longitudinal beams need to be cranked, e.g., for semi-trailers or dumptors, providing locally increased bending stiffness by a locally expanded section area especially at areas of high punctual load induction. Another possible local reinforcement could be realized by inserting reinforcement plates [2, 3].

\section{Comparison of lightweight potential of various materials}

The choice of the best lightweight material has to be made in the context of the design requirements and the load spectrum imposed to the structure. The lightweight potential has to be shown within constraints given by the material itself, the useable designed space and the manufacturability of real parts. An overall cost estimation should not be reduced to the material itself, and it should also consider production, assembly, tooling, maintenance and other cost. Accordingly, it should reflect its proper share on the total cost of ownership to the customer.

An IISI study [4] conducted by the Forschungsgesellschaft Kraftfahrwesen gives a detailed comparison of the mass reduction potential of steel and aluminum for different components of a car body under different load case scenarios. Although the overall weight reduction potential of aluminum is higher than that of high strength steel (HSS) in comparison to a mild steel reference structure, it very much depends on the main load case of a specific component whether a particular weight reduction advantage of aluminum vs. HSS can be found for this component.
The predominant load case for commercial vehicle frames is vertical bending which can be reduced to a simple model of a beam resting on two supports with the distance $l$ equivalent to the wheelbase of the vehicle with one point load $F$ in the middle reflecting the "worst" static load case (see Fig. 1). The profile section should be invariable according to its height $h$ and width $b$ given the assumption that there is only a limited designed space and no material should take advantage by more designed space in comparison to other materials. The only variable should be the required thickness $t$ of the profile section and the material properties, i.e., yield strength $R_{e}$ and density $\rho$. Without harming the general validity of this approach we can also assume $h=b$ to make the calculation as simple as possible.

The section area $A$ can be estimated as

$A \approx 3 b t$.

The second moment of inertia $I$ is mainly depending on the contribution of the flanges which can be estimated as

$I \approx 0.45 b^{3} t$

The section modulus $W$ results as

$W=\frac{2 I}{b}=0.9 b^{2} t$.

The maximum bending moment $M$ that occurs in the middle of the beam at the position where the load $F$ is imposed can be estimated as

$M=\frac{F l}{4}$.

The maximum stress $\sigma$ results as

$\sigma=\frac{M}{W}=\frac{F l}{3.6 b^{2} t}$.

We assume for a simple static load case that the maximum stress $\sigma$ should not exceed the yield strength $R_{e}$ of the material. If we set $\sigma=R_{e}$ we can calculate the required thickness of the profile section

$t=\frac{F l}{3.6 b^{2} R_{e}}$.

The required thickness gives us the required mass $m$ of the beam

$m=\rho A l \approx 3 \rho b t l \approx \frac{5 \rho F l^{2}}{6 b R_{e}}$.

So the required mass is proportional to the ratio of the density and the yield strength of the material, and it can be estimated as

$m \approx \frac{\rho}{R_{e}}$. 


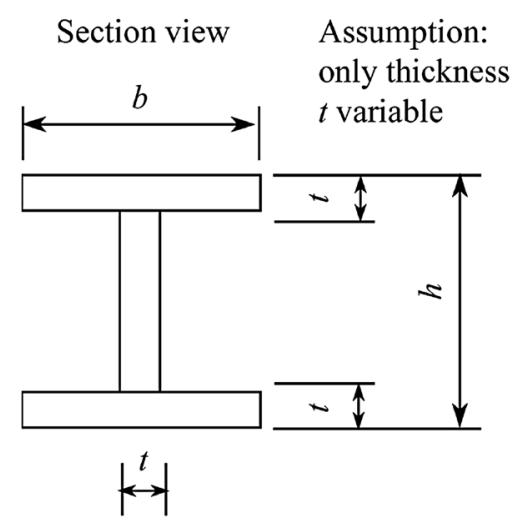

Fig. 1 Simplified vertical bending load case model

A comparison between two materials on the basis of the necessary mass (thickness) needed to bear the maximum force is represented by the ratio $\lambda_{m R}$

$\lambda_{m R}=\frac{\rho_{1} R_{e 2}}{R_{e 1} \rho_{2}}$.

This scenario is applied under the assumption that the only limit is the strength of the material neglecting constraints given by the elastic deformation. If a certain elastic deformation is exceeded, moveable parts as in tautliners or even simple tailboards could be jammed. So under real-life conditions the maximum deformation limit has to be set. The maximum deformation $f$ in the middle of the beam results as

$f=\frac{F l^{3}}{48 E I}$.

where $E$ stands for the Young's modulus, i.e., the stiffness of the material. Given that a certain level of deformation should not be exceeded, the required thickness can be calculated as

$t=\frac{5 F l^{3}}{108 E b^{3} f}$.

This leads to a required mass

$m=\frac{15 \rho F l^{4}}{108 b^{2} E f}$.

So in this case the required mass is proportional to the ratio of the density and the Young's modulus of the material, and it can be estimated as

$m \approx \frac{\rho}{E}$.

A comparison between two materials on the basis of the necessary mass (thickness) needed not to exceed a bending limit is represented by the ratio $\lambda_{m E}$

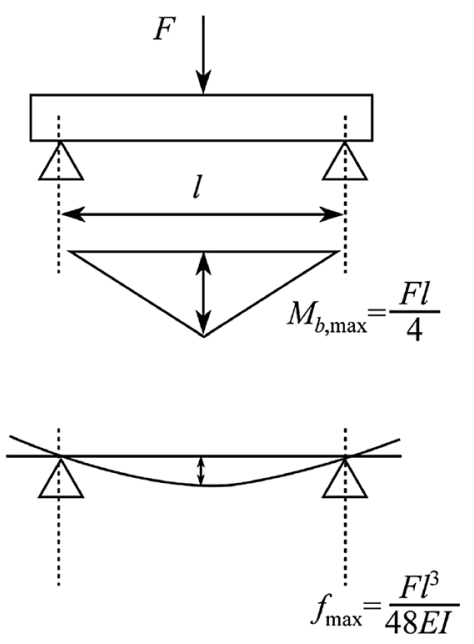

$\lambda_{m E}=\frac{\rho_{1} E_{2}}{E_{1} \rho_{2}}$.

Table 1 contains an overview over the mechanical properties and the lightweight potential of different materials. Mild steel S235 is the reference and $\lambda$ values below 1 are indicating better performance.

Looking only at the ratio of necessary mass and strength $\lambda_{m R}$, high strength steels and light metals are advantageous. Aluminum is on the same level like high strength steel. To limit the maximum bending to a certain value $\left(\lambda_{m E}\right)$ light metals need more mass with the exception of carbon fiber reinforced plastics (CFRP). In this stiffness-driven case, the use of high strength steel does not lead to an advantage as compared to mild steel. Important aspects like material optimized design, metal fatigue especially around joining areas, cost, recycling, etc., have been neglected. The new HSD 700 HD steel grade introduced by the ThyssenKrupp subsidiary Hoesch Hohenlimburg [5] opens new lightweight potential for ultra-high strength microalloyed steel grades with high ductility (approximately $20 \%$ elongation)

Table 1 Comparison of material properties and light weighting potential

\begin{tabular}{lllll}
\hline Material & $\begin{array}{l}\text { Yield strength } \\
\left(R_{e}\right) / \mathrm{MPa}\end{array}$ & $\begin{array}{l}\text { Young's modulus } \\
(E) / \mathrm{GPa}\end{array}$ & $\lambda_{m R}$ & $\lambda_{m E}$ \\
\hline S235 & 235 & 210 & 1.00 & 1.0 \\
S460 M & 460 & 210 & 0.50 & 1.0 \\
S700HD & 700 & 210 & 0.30 & 1.0 \\
EN-GJL200 & 200 & 100 & 1.10 & 1.9 \\
AlMgSi T6 & 160 & 70 & 0.50 & 1.0 \\
MgA16Zn & 175 & 44 & 0.30 & 1.1 \\
GF-EP (50\% GF) & 270 & 37 & 0.20 & 1.4 \\
CF-EP (50\% CF) & 330 & 120 & 0.16 & 0.4 \\
Ti & 250 & 105 & 0.50 & 1.1 \\
\hline
\end{tabular}


and low carbon content (maximum 0.06\%). These excellent material properties could be reached by using an innovative low-carbon steel chemistry in combination with increased niobium microalloying.

\section{Geometry-driven lightweight construction}

By only varying the section with the same material the weight changes proportionally to the section area. The goal is to choose the optimal geometry to reach the maximum load capacity with minimal material use - independent from any specific material. One main constraint for this optimization method is the increasing risks of buckling the thinner the sections are designed [6]. Without putting the general validity in question, a simple model of a cantilever beam can be used to demonstrate the lightweight design potential.

A round full material section, which remains constant over the full beam length, is taken as a reference to start with (see Fig. 2). In order to save weight, the first step would be changing the section in a way that material use is minimized while keeping the section modulus $W$ on the same level. The example shows that the use of a U-shaped profile can reduce the weight to one third of the reference. Further weight reduction would be theoretically possible by a further extension of the designed space and a further reduction of the thickness. Yet an easy and cost efficient design would not be realistic because of buckling and other higher degree stability problems.

The next step would be a change of the section over length in order to reach a homogeneous maximum allowed stress level $\sigma$ for optimum utilization of the material strength. The manufacturing of a cranked beam with variable sections is usually done by welding separate flanges on a web. German trailer producer Schmitz

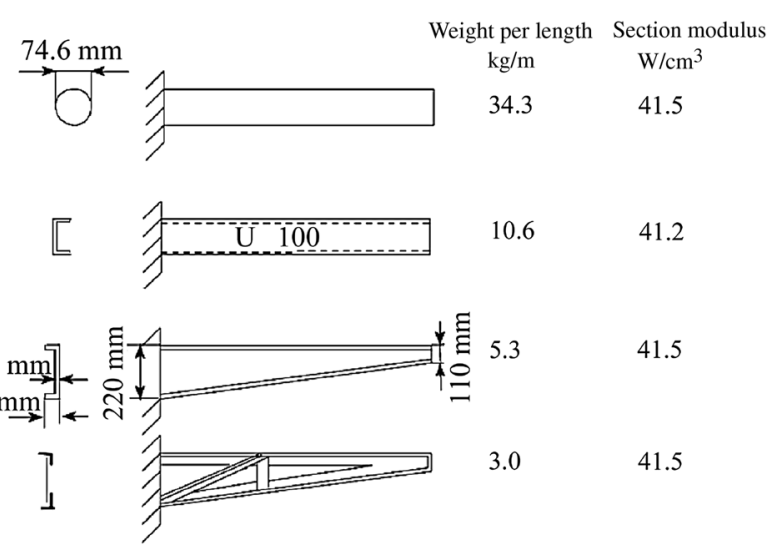

Fig. 2 Different stages of topology optimized mass reduction for a cantilever
Cargobull [7] has recently introduced flexible roll forming as a new manufacturing method for the series production of semi-trailer beams. This innovative manufacturing method avoids welds in highly stressed areas and reduces thermal deformation leading to residual stress.

Finally, the optimum solution would be the replacement of the web, which is still showing an unequal stress distribution. This can be achieved by struts leading alongside the areas of high stresses, which have been identified by a finite element analysis. In comparison to the full section reference this would diminish weight to less than $10 \%$ of the reference section. From an assembly point of view, however, this solution is not practical because the web is also needed to fix many attachment parts along the side member.

The more elaborately the lightweight structure is designed, the more important the profound knowledge about the load spectrum in real-life use. This is because the structure becomes increasingly vulnerable against any load that has not been considered within the optimization loop. There are already several studies proving that the aforementioned lightweight potential assumptions based on simplified theoretical models can be achieved under reallife conditions. A lightweight design study for a vehicle sub-frame conducted by ThyssenKrupp Steel Europe [8] shows that advanced high strength steel in combination with innovative semi-finished parts such as tailored products can achieve almost the same weight reduction as an advanced aluminum design, yet at half the cost. Swedish steelmaker SSAB demonstrated in several lightweight studies for trucks and trailers a weight reduction potential of more than $20 \%$ by using advanced high strength steel in the structure [9]. This comes at very moderate material cost increase. This moderate cost increase however is overcompensated during in the vehicle use phase due to fuel savings and higher loading capacity.

\section{Node design considerations}

Node design is the crucial point in terms of lightweight performance of constructions consisting of different profiles. Most structural failures occur in areas where parts are joined though the reasons for failure can vary. In many cases the material itself is not the origin of the problem. Yet the joining process and the design of the joints offer many potential risks lying in the designed topology. Following basic rules for the design of different node types can minimize these risks.

The commonest node type is the intersection between a longitudinal beam and a cross member. When these parts are joined it is very important that free warping of the flanges is possible when the structure is loaded. 
High stress peaks will occur in the weld if welding blocks the free movement of the flanges under load (see Fig. 3). Consequently, fatigue cracks will occur after a short time. The best solution is to weld only the webs of both profiles as indicated in Fig. 4.

The same rule is applied for vertical struts. It is also very important that the joining area of the two profiles does not create a locally closed section on top of an entirely open profile section (see Fig. 5). This will lead to an abrupt change in stiffness and therefore cause stress peaks in this area.

Another important aspect concerning vertical loads being introduced into open profile sections is an additional torsion moment caused by this vertical load. The larger the distance of the vertical force line from the shear center, the higher the torsional moment induced by the vertical force becomes (see Fig. 6). Ideally, vertical forces should be introduced close to the shear center, e.g., by attaching consoles close to this point.

In some cases local reinforcements of open profiles are necessary to support it against collapsing under a high single load. Web plates should then be placed in a way that the profile section is not partially closed to avoid abrupt changes in stiffness (see Fig. 7).
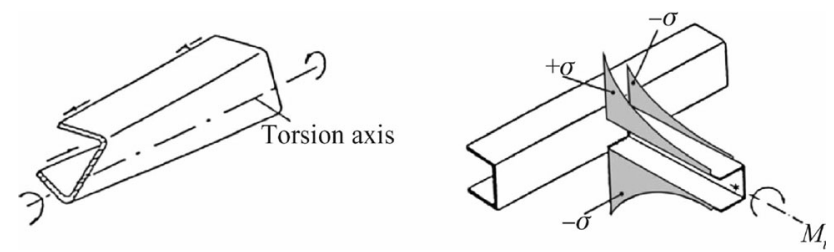

Fig. 3 Stress peaks caused by blocking free warping of the flanges under torsion [10]

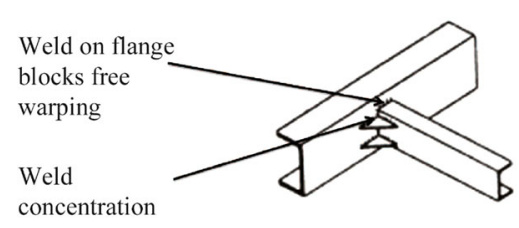

(a)

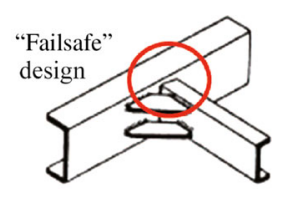

(b)

Fig. 4 Inferior a and superior $\mathbf{b}$ cross member attachment [11]

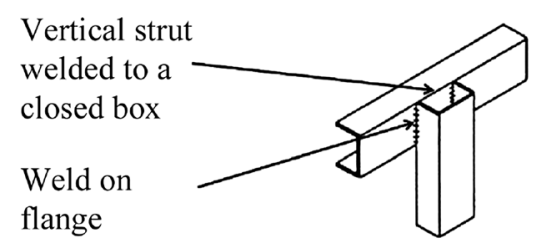

(a)
The Brazilian mining company Companhia Brasileira de Metalurgia e Mineração (CBMM) conducted a design change of their dump trucks by upgrading from mild steel to high strength niobium microalloyed steel having yield strength above $700 \mathrm{MPa}$ and accordingly reducing the part thickness. Furthermore, weld concentration and stress peaks in welded areas were eliminated by a design change.

A weight reduction of more than $1900 \mathrm{~kg}$ was achieved leading to an increased loading capacity of $1.5 \mathrm{t}$ (see Fig. 8). Higher cost of the upgraded steel and manufacturing caused a price increase of the truck. However this additional cost could be compensated within less than one year of operation because of increased loading capacity, reduced fuel consumption and reduced consumption of tires.

\section{Achievements by Chinese truck manufacturers}

Dongfeng Motor Co. realized several weight reducing solutions over the last years exploiting design changes as well as material upgrades. Topology changes in the main frame and the angle sheet achieved weight losses of around $84 \mathrm{~kg}$ and $96 \mathrm{~kg}$, respectively. The use of high strength steel in the frame area has been established to the following levels:

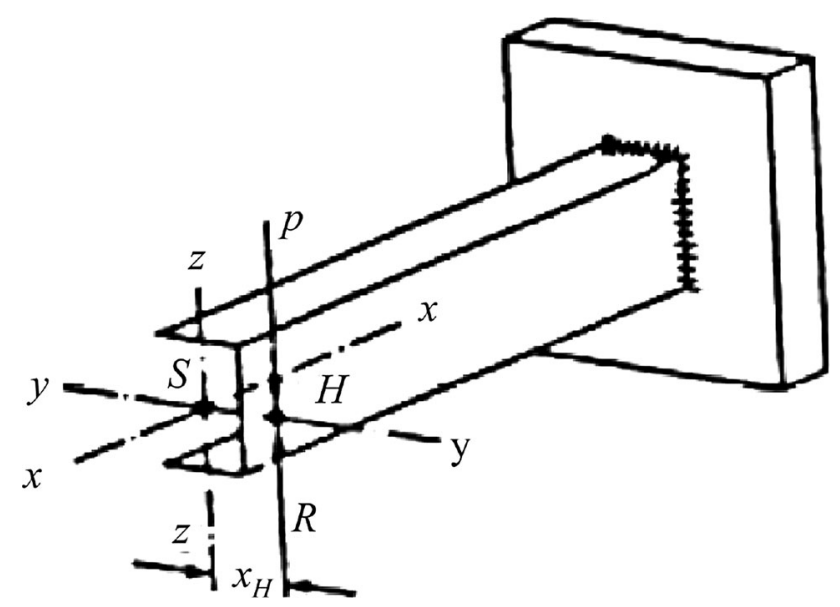

Fig. 6 Position of the share centre of a U-shaped section

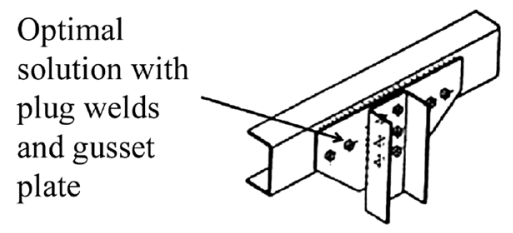

(b)

Fig. 5 Inferior a and superior b vertical strut attachment 


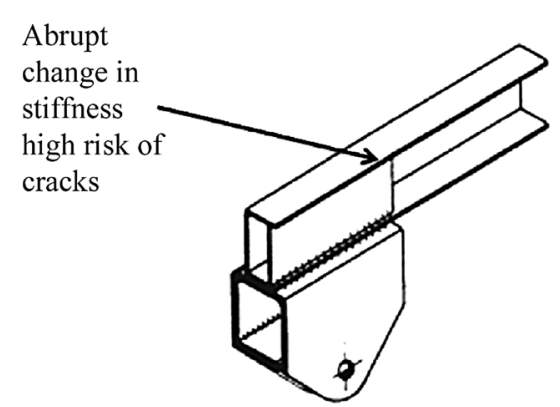

(a)

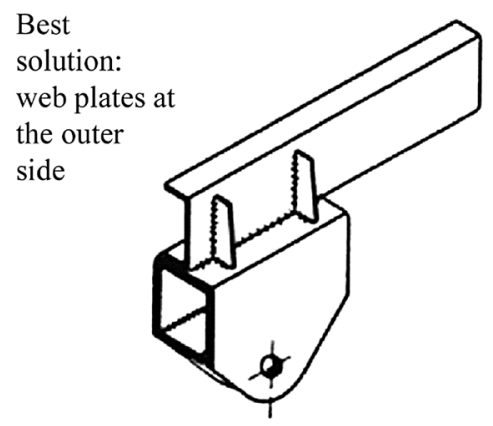

(b)

Fig. 7 Inferior $\mathbf{a}$ and superior $\mathbf{b}$ solution for a vertical reinforcement of an open section

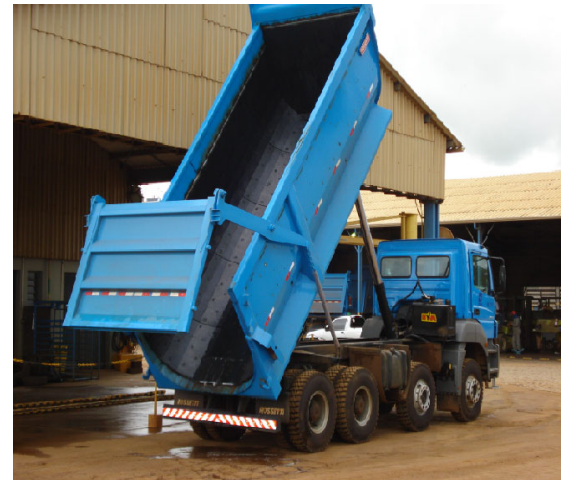

Truck (Actros 4844, model 2010) $=11074 \mathrm{~kg}$ Dumper + liner $($ Rossetti, model 2010) $=7426 \mathrm{~kg}$ Total weight $=18500 \mathrm{~kg}$

(a) Conventional design

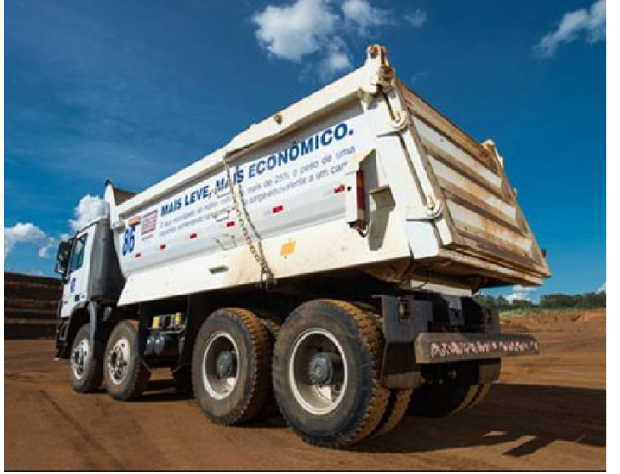

Truck $($ Actros 4844, model 2013) $=11530 \mathrm{~kg}$ Dumper + liner (Rossetti, model 2013) $=5470 \mathrm{~kg}$ Total weight $=17000 \mathrm{~kg}$

(b) Optimized design

Fig. 8 Weight reduction of a dump truck by upgrading to high strength steel
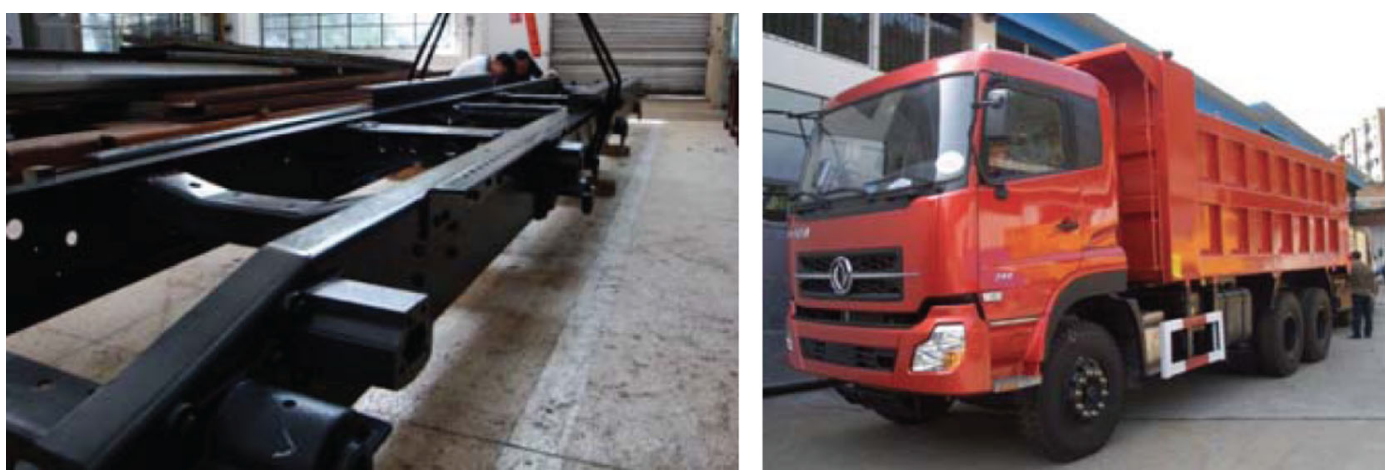

Fig. 9 Weight reduction of $250 \mathrm{~kg}$ in a dump truck by upgrading to D700L steel grade (Dongfeng)

- Longitudinal beam: 600-700 MPa

- Cross beam: 510-600 MPa

- Brackets: 440-510 MPa

The weight reduction achieved by this material upgrade from originally conventional carbon steel is in the order of $150 \mathrm{~kg}$.
In dump trucks the frame beam gages could be subsequently reduced from originally $(8+8) \mathrm{mm}$ to $(8+6) \mathrm{mm}$ and $(8+4) \mathrm{mm}$. A further tensile strength increase to $1200 \mathrm{MPa}$ by using heat-treated steel allowed applying $8 \mathrm{~mm}$ single gage beams. This brings a $25 \%(140 \mathrm{~kg})$ weight saving as compared to the $(8+4) \mathrm{mm}$ beam 

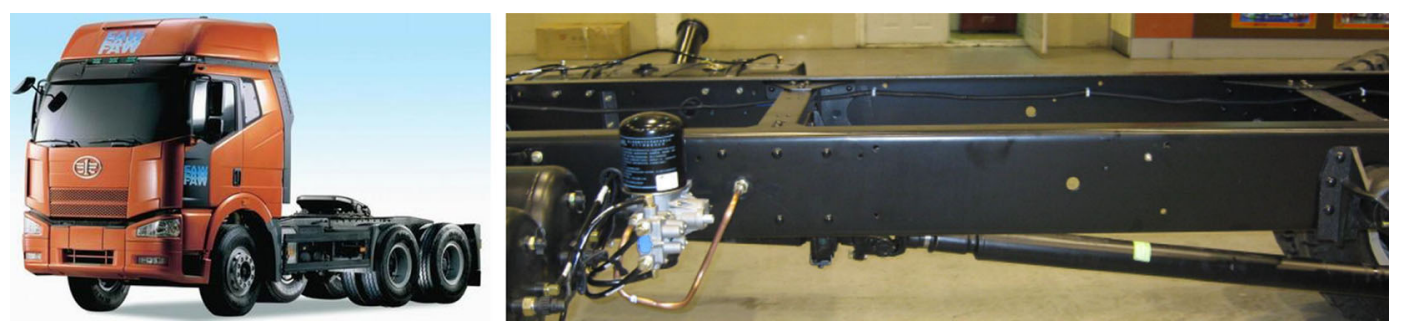

Fig.10 Weight reduction of $150 \mathrm{~kg}$ by using HSS in the frame structure (FAW)

Table 2 Light weighting achievements in various FAW trucks

\begin{tabular}{lll}
\hline Model & Applied optimization & Weight reduction \\
\hline $\mathrm{J} 5 \mathrm{M}$ & Reduce height of HSS beam to $280 \mathrm{~mm}$ from former $320 \mathrm{~mm}$ & $21 \mathrm{~kg} / \mathrm{m}$ \\
$\mathrm{J} 5 \mathrm{M}$ & Reduce gage of HSS beam to $7 \mathrm{~mm}$ from former $8 \mathrm{~mm}$ & $6.6 \mathrm{~kg} / \mathrm{m}$ \\
$\mathrm{J} 5 \mathrm{~K}$ & Use of single-gage frame design & $21.5 \mathrm{~kg} / \mathrm{m}$ \\
$\mathrm{J} 5 \mathrm{M}-8 \times 4$ & Lightweight technology and batch production & $700 \mathrm{~kg}$ \\
\hline
\end{tabular}

structure. However the significant strength increase by heat treatment did not reflect in a similar increase of fatigue resistance.

The weight of dump trucks could be reduced by up to $250 \mathrm{~kg}$ when replacing the formerly used D510L steel grade by $\mathrm{D} 700 \mathrm{~L}$ ultrahigh strength steel for the beams in the dumper. The replacement of steel grade Q235 by thinner-gaged high strength steel for the box section resulted in a weight reduction of $1840 \mathrm{~kg}$ (see Fig. 9).

The HSS of $500 \mathrm{MPa}$ minimum yield strength was developed by Baoshan Iron \& Steel Co. Ltd. for longitudinal beams and applied in a newly designed truck by the First Automobile Works (FAW). Compared with traditional $16 \mathrm{Mn}$ steel, yield strength has been increased by $43 \%$ and the fatigue strength increased by $44 \%$. The current use of $500 \mathrm{MPa}$ steels for single gage beams reduced the weight by around $150 \mathrm{~kg}$ (see Fig. 10). Several other achievements of weight reduction at FAW commercial vehicles could be realized, as shown in Table 2 .

The application of roll-formed beams made from steel grade $700 \mathrm{~L}$ with gage of $10 \mathrm{~mm}$ could replace conventional $(8+5) \mathrm{mm}$ design resulting in a weight reduction of $29 \%$. FAW also started using ultrahigh strength steel of $700 \mathrm{MPa}$ yield strength (grade 900L), which will be the priority for the commercial vehicle construction in the future.

\section{Conclusions and outlook}

In commercial vehicle frame structures, high strength steel shows the most attractive combination of weight saving potential and cost. In order to achieve the maximum lightweight performance with regard to the entire structure, the main goal is to avoid potential performance losses due to local effects especially in connecting areas. While in Europe high strength steel such as the S700 grade is already widely used in commercial vehicle frame structures, vehicle manufacturers in the emerging markets are recently intensifying their research and development activities concerning the application of ultrahigh strength steel grades. Close cooperation with the local steel mills has been established in China. A joint and comprehensive development comprising the whole process chain from the metallurgy down to the final product led to impressive weight saving results in the vehicle structure. This came without compromising manufacturability like forming and welding and keeping the overall costs on an acceptable level. Finally, it is the task of material suppliers and vehicle manufacturers to convince their customers, i.e., the truck operators of the benefits of lightweight design. This can be achieved by demonstrating that lightweight design does not lead to any loss of robustness in the daily operation of the vehicle. Field trials have demonstrated that the cost of ownership actually decreases with weight-optimized commercial vehicles. Modern high strength steel grades provide the best potential in this respect.

Open Access This article is distributed under the terms of the Creative Commons Attribution License which permits any use, distribution, and reproduction in any medium, provided the original author(s) and the source are credited.

\section{References}

1. Pippert H (1998) Car body technology: commercial vehicle superstructures and chassis frames. Vogel Verlag, Berlin, pp 120-145 
2. Truck MAN, Bus AG (2014) MAN guidelines to fitting bodies truck Series TGS/TGX Edition 2014 V2.0. https://www.manted. de/manted/aufbaurichtlinien/gb_all.html

3. Mercedes-Benz AG (2012) Body/equipment mounting directives truck. https://www.manted.de/manted/aufbaurichtlinien/d_tgs_ tgx.html. Accessed 01 Dec 2012

4. Wohlecker R, Henn R (2009) Mass reduction potential of steel and aluminum in automotive applications. In: SAE international journal of material and manufacturing, pp 480-484

5. Gruss M, Nagel M, Höfel P (2012) HD-High-ductility, lowalloy, fine-grain structural steels. In: ThyssenKrupp Techforum, pp 28-31

6. Klein B (2013) Buckling of plates and tubes. Lightweight design: computation and design fundamentals. Vieweg+Teubner Verlag, Berlin, pp 232-258
7. Schmitz Cargobull http://www.cargobull.com/de/MODULOSFahrzeugrahmen-MODULOS-Chassis_310_689.html. Accessed 8 Jan 2015

8. Seyfried P, Sudowe U (2007) SLC: the innovative, low-cost lightweight construction solution for passenger car subframes. In: ThyssenKrupp techforum, pp 20-23

9. SSAB-Swedish steel $\mathrm{AB}$ company brochures Domex high strength steel. www.ssab.com

10. Appel W (2013) Commercial vehicle frames and superstructures. In: Commercial vehicle technology, Vieweg+Teubner Verlag, Berlin, pp 303-373

11. Spangenberg D (2014) The design of machines and vehicles moving on bumpy roads. Fundamentals of agricultural engineering-edited volume, vol 12 